\section{Insulin, plasma volume and haematocrit}

Dear Sir,

Several studies have now shown that i.v. injection of insulin decreases the plasma volume [1-4]. Insulin may decrease the plasma volume by two different mechanisms: 1) indirectly by increasing plasma adrenaline during hypoglycaemia [3,5], and 2) directly by a nonadrenergic mechanism in diabetic patients during hyperglycaemia and in normal subjects during a euglycaemic glucose clamp $[1,4]$. The first mechanism only is associated with an increase in haematocrit. This increase in haematocrit is mediated by an alpha-adrenergic mechanism and is due to elevated plasma adrenaline levels, which increase postcapillary resistance [5]. Parving et al. [6] suggested that the decrease in plasma volume after insulin injection during eu- or hyperglycaemia was factitious and due to inadequate mixing of tracer and plasma, because the haematocrit did not increase and plasma volumes were not significantly different after insulin injection and in control experiments if plasma volumes were calculated $20 \mathrm{~min}$ rather than 10 min after injection of the tracer. We have observed, however, markedly lower plasma volumes after insulin even $30 \mathrm{~min}$ after tracer injection $[4$, and unpublished observation] indicating that the decrease in plasma volume after insulin during euglycaemia is real. We suggest that the non-adrenergic mediated plasma volume lowering effect of insulin is due to an increase in muscle capillary blood flow.

One of the most marked changes in haemodynamics after injection of insulin is an increase in muscle blood flow [7]. It is also wellestablished that microvascular haematocrit is lower than systemic haematocrit mainly due to plasma skimming. This phenomenon is flow dependent and elevated flow rates reduce the difference between microvascular and systemic haematocrits [8]. One would, therefore, expect a decrease in venous and systemic haematocrit after increments in capillary or nutritive blood flow. This is not observed probably because at the same time plasma is lost to the extracellular fluid due to the concomitant increase in capillary surface area. These two processes, which have opposite effects on venous haematocrit are related as both of them are dependent on the relative increase in capillary blood flow.

Our hypothesis indicates that insulin and adrenaline (through a beta-adrenergic mechanism) by increasing capillary blood flow may decrease plasma volume without changing venous haematocrit. It may also explain a lack of correlation between changes in haematocrit and plasma volume observed during adrenaline infusion [4]. Furthermore, in the latter study infusion of noradrenaline and adrenaline in relatively high doses both increased the haematocrit to approximately the same extent, whereas the decrease in plasma volume was twice as high during adrenaline infusion as compared with infusion of noradrenaline. Further studies are in progress to test the hypothesis that the decrease in plasma volume observed during euglycaemia after insulin is a consequence of an increase in nutritive blood flow.

Insulin has also been shown to increase transcapillary escape rate of plasma albumin both during euglycaemia and during insulin hypo- glycaemia [1, 3, 4]. Christensen et al. [9] showed that $i$. v. injection of insulin increased urinary albumin excretion rate by a glomerular mechanism. This phenomenon was not due to changes in blood glucose concentrations. The effect of insulin on the transcapillary escape rate of plasma albumin cannot, however, be mimicked by adrenaline infusion [4] and remains to be explained.

Yours sincerely,

N.J.Christensen and J.Hilsted

\section{References}

1. Gundersen HJG, Christensen NJ (1977) Intravenous insulin causing loss of intravascular water and albumin and increased adrenergic nervous activity in diabetics. Diabetes 26: 551-577

2. Mackay JD, Hayakawa H, Watkins PJ (1978) Cardiovascular effects of insulin: plasma volume changes in diabetics. Diabetologia 15: $453-457$

3. Hilsted J, Bonde-Petersen F, Madsbad S, Parving H-H, Christensen NJ, Adelhøj B, Bigler D, Sjøntoft E (1985) Changes in plasma volume, in transcapillary escape rate of albumin and in subcutaneous blood flow during hypoglycemia in man. Clin Sci 69: 273-277

4. Hilsted J, Christensen NJ, Larsen S (1989) Effect of catecholamines and insulin on plasma volume and intravascular mass of albumin in man. Clin Sci 77: 149-155

5. Frier BM, Corrall RJM, Davidson NMcD, Webber RG, Dewar A, French EB (1983) Peripheral blood cell changes in response to acute hypoglycemia in man. Eur J Clin Invest 13: 33-39

6. Parving H-H, Noer I, Deckert T, Lassen NA (1979) Intravenous insulin has no effect on transcapillary escape rate of albumin and on plasma volume in short-term juvenile diabetics. Diabetes 28 : 282-286

7. Liang C-S, Doherty JU, Faillace R, Maekawa K, Arnold S, Gavras $\mathrm{H}$, Hood Jr WB (1982) Insulin infusion in conscious dogs. Effects on systemic and coronary hemodynamics, regional blood flows, and plasma catecholamines. J Clin Invest 69: 1321-1336

8. Klitzman B, Duling BR (1979) Microvascular hematocrit and red cell flow in resting and contracting striated muscle. Am J Physiol 237: H481-H490

9. Christensen NJ, Gundersen HJG, Hegedüs L, Jacobsen F, Mogensen CE, Østerby R, Vittinghus E (1980) Acute effects of insulin on plasma noradrenaline and the cardiovascular system. Metabolism 29 [Suppl 1]: 1138-1145

Dr. N.J.Christensen

Department of Internal Medicine and Endocrinology

Herlev University Hospital

DK-2730 Herlev

Denmark

\title{
Announcements
}

\section{Lions Clubs International Foundation}

The American Diabetes Association will administer the 1989-1990 LCIF Clinical Research Program in Diabetic Eye Disease. This program supports clinical or applied research in diabetic retinopathy in the United States and throughout the world. Awards, up to $\$ 40,000$ per year for two years, will be given to support research in new treatment regimens for diabetic retinopathy, epidemiology studies, and research that facilitates the translation of basic knowledge to clinical application (e.g. the development and implementation of screening programs). In addition, funds will be awarded to support the training of foreign investigators in research institutions located in the USA; to enable investigators from the USA to conduct training programs in foreign institutions; and to provide equipment for the conduct of clinical research in diabetic retinopathy. The deadline for receipi of applications: February 2, 1990. For further information and application forms please contact: American Diabetes Association, Inc., National Service Center, 1660 Duke Street, Alexandria, Virginia 22314. ATTN: LCIF Clinical Research Program in Diabetic Eye Disease.

\section{2nd International Symposium on the Immunotherapy of Type 1 Diabetes}

This symposium will be held from September 9-10, 1990 at the St. Bartholomew's Hospital, London, UK. The Symposium is the official meeting of the International Diabetes Immunotherapy group (IDIG) and will deal with all aspects concerning strategies in the immunotherapy and prevention of Type 1 diabetes. For further information please contact: Anne Glover, Department of Diabetes and Immunogenetics, Dominion House, St. Bartholomew's Hospital, London EC1A 7BE United Kingdom. Tel.: 01-601 7447. 